\title{
Health behaviors of patients diagnosed with type 2 diabetes mellitus and their influence on the patients' satisfaction with life
}

This article was published in the following Dove Press journal:

Therapeutics and Clinical Risk Management

25 November 2016

Number of times this article has been viewed

\author{
Anna Rosiek' \\ Tomasz Kornatowski ${ }^{1}$ \\ Natalia Frąckowiak- \\ Maciejewska' \\ Aleksandra Rosiek- \\ Kryszewska ${ }^{2}$ \\ Przemysław Wyżgowski ${ }^{3}$ \\ Krzysztof Leksowski ${ }^{1,3}$ \\ 'Department of Public Health, \\ Faculty of Health Science, Nicolaus \\ Copernicus University in Toruń, \\ ${ }^{2}$ Department of Inorganic and \\ Analytical Chemistry, Faculty of \\ Pharmacy, Nicolaus Copernicus \\ University in Toruń, ${ }^{3}$ Department \\ of General Surgery, I0th Military \\ Hospital, Bydgoszcz, Poland
}

Background: The diagnosis of type 2 diabetes mellitus (T2DM) carries with it a number of changes to the patient's lifestyle. A healthy lifestyle, health and preventive behaviors, as well as healthy nutrition habits play a key role in treating T2DM as well as limiting its complications.

Materials and methods: The aim of this study was the analysis of the correlation of T2DM patients' health behaviors and their influence on the patients' quality of life. The study was performed on a group of 50 patients from the Kuyavian-Pomeranian Voivodeship. In this study, the Health Behavior Inventory and the Satisfaction with Life Scale were used. The results were statistically analyzed. The study was approved by the ethics committee.

Results: The intensity of severity of health behavior and satisfaction with life of T2DM patients depends on the gender of the patient $(P<0.05)$. The analysis of the patients' behaviors in four categories, proper eating habits (consuming vegetables, fruit, whole meal bread), health practices (daily physical activity, recreation, sleeping habits), preventive behaviors (including keeping to health recommendations), and positive mental attitude, showed substantial correlation of the Health Behavior Inventory and the Satisfaction with Life Scale $(P<0.05)$.

Conclusion: The categorization of the prohealth behaviors shown by diabetics allowed us to measure the connection between the individual categories of satisfaction with life. Males with T2DM showed a higher satisfaction with life score than females with the same diagnosis. The analysis showed that patients with a higher intensity of health behaviors also had superior health behaviors. The resulting correlations prove a notable relationship.

Keywords: living with diabetes, experience and perception of patients, type 2 diabetes, health behaviors, satisfaction with life, lifestyle, noncommunicable diseases

\section{Introduction}

The aim of the study was to analyze the correlation of health behaviors of patients diagnosed with type 2 diabetes mellitus (T2DM) and their influence on the patients' quality of life.

T2DM is a chronic disease which often develops for years without any clinical symptoms. ${ }^{1-7}$ It is the most common type of diabetes worldwide, the other two common types being type 1 diabetes and gestational diabetes. T2DM accounts for $85 \%-95 \%$ of diagnosed cases. ${ }^{8}$ Diabetes as well as other diseases of affluence which include obesity and cardiovascular diseases are a major health concern in the 21 st century. It is estimated that by 2025 , the number of patients with diabetes around the world will have increased to over 330 million (which will account for about $6.5 \%$ of the world's population $)^{9}$ and by 2035 , the number could increase to almost 600 million. ${ }^{10}$
Correspondence: Anna Rosiek Department of Public Health, Faculty of Health Science, Nicolaus Copernicus University in Toruń, Przod. Pracy 8/7, 85-843 Bydgoszcz, Poland Email ania.rosiek@wp.pl 
In Poland, in 2006, there were 2 million people diagnosed with T2DM. This number meant a prevalence of 5\% among the Polish population. ${ }^{11}$

A major factor which leads to a constant increase in the number of people with T2DM includes the changes in the lifestyle globally resulting from social advancement and quick urbanization. ${ }^{12,13}$ Some of them are a sedentary lifestyle, not conforming to healthy nutrition recommendations, including eating large quantities of processed foods, stress, and exhaustion. This applies not only to developed countries, but also to countries with medium or low social status of their citizens. ${ }^{14,15}$ The problem of incidence of this disease applies to the whole world, regardless of the social status. ${ }^{16}$ Diabetes, then, is not only a health issue, but also an economic one. A large percentage of people with T2DM are middle aged and at the top of professional and economic productivity. ${ }^{17}$

The costs connected with treating diabetes and caring for patients are extensive all over the world. This is due to the costs involved in frequent outpatient visits, the patient's drug use, and frequent hospitalizations. T2DM patient care is a long-term affair and often lasts until the end of the patient's life. ${ }^{14}$ It is estimated that by 2025 , the worldwide cost of treatment of T2DM will have reached around 302 billion dollars. ${ }^{8}$ In Poland, the highest share of T2DM treatment costs is contributed by the costs of insulin therapy (over 45\%) and of hospital-based treatment (around 25\%). Outpatient visits are the least cost-intensive (around 3\%). Globally, the costs take similar shape. ${ }^{8}$ Among the costs indirectly connected to diabetes treatment are the costs connected to a decrease in productivity because of early retirement, disability benefits, and the decrease in productivity due to sick leaves. ${ }^{11}$

The approach to patient treatment is increasingly multidisciplinary and holistic. Attention is given not only to the results of physical examination, but also to the quality of life of the patient from the moment of diagnosis. To measure them, appropriate tools such as quality of life questionnaires customized for every disease, including diabetes, are used. The questions are related to the issues of well-being, satisfaction with life, physical state, emotions, social functioning, and daily blood glucose levels. The use of questionnaires about satisfaction with life for diabetic patients is uncommon in Poland. Making their use more prevalent would be a good way of discovering the symptoms and problems which negatively influence the quality of life of the patient. Furthermore, patients would have a sense of greater involvement on the part of the doctors, which would positively influence the patients' satisfaction with their medical care and lead to a general improvement of satisfaction with their life. ${ }^{18}$
The disease and the frequent visits to specialist doctors and diabetes clinics, the daily intake of medicine to lower the blood glucose levels, insulin injections, hospitalizations, and the risk of complications which, in extreme cases, could lead to the patient's death drastically lower the quality and satisfaction with life of people with T2DM. The disease influences not only the physical well-being, but also the mental sphere, social functioning, and everyday existence. ${ }^{19}$ In order to improve the quality of life of the patients, changes must be made in their lifestyle. These changes include lowering the body mass, new dietary habits, and physical activity which may stop the development of the disease. ${ }^{19,20}$ Changes to one's habits and lifestyle are often difficult to accept because of their extent. For a patient with T2DM, the support of private and public entities, such as the government, health organizations, doctors, and specialists, as well as the society as a whole, is crucial. ${ }^{20}$ Integrated care allowing complex, conscious, and full realization of the treatment aims influences both the improvement of health and the improvement of the quality of life. ${ }^{21}$

The quality of life in everyday functioning manifests itself as satisfaction, self-acceptance, and being able to realize one's goals. An important factor that helps patients suffering from T2DM is health education. It aims to improve the patients' knowledge so that they can actively take part in the treatment, make use of the results of controlling the modifications to therapy, and prevent chronic complications. Gaining knowledge about the disease leads to a decrease in the sense of fear and in the sense of being disabled. A proper informative course about insulin therapy broadens the patients' knowledge and skills, influences their sense of independence and self-reliance, and lowers the fear and doubts associated with the disease. It also influences the health behaviors and satisfaction with life of the patient struggling with a chronic disease. 22,23

Quality of life is measured as physical and social functioning, and perceived physical and mental well-being. People with diabetes have a worse quality of life than people with no chronic illness, but a better quality of life than people with most other serious chronic diseases. ${ }^{24}$ Previous studies investigating the associations between health behaviors and life satisfaction in adults with diabetes have reported mixed findings. One such study has examined the impact of satisfaction on global life satisfaction. ${ }^{25}$ In some studies, healthrelated quality of life was found to have a modest effect on overall life satisfaction in the general population compared to satisfaction in other domains, ${ }^{26-28}$ but its effect was larger when focusing on those who experienced major decrements in health status. ${ }^{24}$ The past few years have seen an increase 
in research focusing on the relationship between behaviors such as glycemic control and life satisfaction in people with diabetes. A number of these studies suggest that a relationship between health behavior and life satisfaction does exist. ${ }^{28,29}$ Studies of clinical and educational interventions suggest that improving the patients' health status and their perceived ability to control disease results in improved quality of life and provides satisfaction in life to patients. ${ }^{29}$ Also, some studies have found significant associations between quality of life and measures of glycemia ${ }^{30}$ and increased treatment satisfaction. ${ }^{24,31}$ Several studies have reported that increased duration of diabetes was associated with decreased quality of life in population of people with each type of diabetes. ${ }^{28,32,33}$ On the other hand, some studies have found no significant association between the quality of life and disease duration. ${ }^{34}$ For example, Finnish and Swedish studies of patients with diabetes found no significant relationship between disease duration and scores on the Finnish or Swedish version of scale of satisfaction. ${ }^{29,32}$

Also, some previous studies have looked at the associations between health behaviors like physical activity and diet and life satisfaction, ${ }^{19}$ but these questions have never been investigated in a Polish population and they have reported mixed findings. Moreover, there are possible gender differences in health behaviors or satisfaction with life. A number of researchers have reported that quality of life is better among diabetic men than among diabetic women. ${ }^{35-40}$ This is consistent with the reported gender differences in health behaviors of patients diagnosed with T2DM and their influence on the patients' satisfaction with life. This aspect also has never been studied in the Polish population. This study addresses the gaps in the literature and needs to be highlighted.

\section{Materials and methods}

This study was conducted on a group of 50 patients from the Kuyavian-Pomeranian Voivodeship between April and December 2015. All participants were people diagnosed with T2DM in the last 5 years before starting the research. Participants were in a good health status and were under regular control by diabetologist. In this study, the Health Behavior Inventory (IZZ) and the Satisfaction with Life Scale (SWLS) were used. Patients were examined before planned control visits to a doctor. At the same time, they completed two questionnaires (first IZZ and then SWLS). Patients with depression as a comorbidity were excluded from the study. The results of both SWLS and IZZ were converted into standard ten (sten) scores. (The sten is a standard scoring system commonly used with personality questionnaires. Stens divide the score scale into ten units. Each unit has a bandwidth of half a standard deviation except the highest unit [Sten 10], which extends from 2 standard deviations above the mean, and the lowest unit [Sten 1], which extends from 2 standard deviations below the mean. ${ }^{41}$ ) A score within 1-4 represents a low value, sten 5 and 6 are regarded as average, and a score of 7-10 regarded as a high sten. The IZZ is composed of 24 statements which describe different behaviors of the patient connected to their health. The IZZ is a standardized method according to Juczyński. ${ }^{42}$ The frequency of individual behaviors as stated by the subjects allows to determine the frequency of patients' health behaviors in four categories: proper eating habits (consuming vegetables, fruit, whole meal bread), health practices (daily physical activity, recreation, sleeping habits), preventive behaviors (including keeping to health recommendations), and positive mental attitude of the patient. The categorization of the diabetic's behaviors enables to gauge whether the patient's knowledge in these categories is sufficient for self-care and whether there is a relationship between these categories and the patient's satisfaction with life.

To this end, the SWLS was used. SWLS is also a standardized method. ${ }^{43,44}$ It is composed of five statements connected with the T2DM patients' general sense of being satisfied with life. Spearman's rank correlation coefficient was used for calculation of the strength of the relationship in the four categories. The strength of the correlations ( $r$ Spearman) was determined according to the following criteria:

below $\pm 0.2 \quad \rightarrow \quad$ slight correlation (almost negligible relationship)

from \pm 0.2 to $\pm 0.4 \rightarrow$ low correlation (definite relationship)

from \pm 0.4 to $\pm 0.6 \rightarrow$ moderate correlation (substantial relationship)

from \pm 0.6 to $\pm 0.8 \rightarrow$ high correlation (marked relationship)

from \pm 0.8 to $\pm 0.9 \rightarrow$ very high correlation (very dependable relationship)

from \pm 0.9 to $\pm 1.0 \rightarrow$ practically complete correlation.

Scatter diagrams which show the cardinality of concurrent points with coordinates determined by two variables in order to emphasize the different weights of the points were used for the presentation of parametric dependence.

Box-and-whisker plots with a mean, a mean \pm standard error, and a mean \pm standard deviation were used for the presentation of nonparametric dependencies. For the calculation of nonparametric dependencies and testing the significance of differences between mean values, the analysis of 
variance (ANOVA) was used. The results were statistically analyzed using descriptive statistics and tests of statistical significance.

For verification of all analyses, a significance factor at the level of $\alpha=0.05$ was used, which allowed the variables to be considered statistically significant at $P<0.05$.

The Institutional Biomedical Ethics Committee approved this study (file number KB 323/2015). Written informed consent was obtained from participants of the study for participation in the study and publication of this report.

\section{Results}

The results are discussed in correlation to the categories.

\section{Demographic data}

The study group included 50 people of whom $34 \%$ were men (17 subjects) and 66\% were women (33 subjects).

\section{Gender}

Statistical analysis of the results of the IZZ questionnaire showed that gender affects the intensity of health behaviors related to T2DM in a statistically significant way. Women had lower values $(P<0.05)$. The values obtained indicate that women are more likely than men to experience a lower intensity of health behaviors. The test result of $F$ in ANOVA was $F=10.94, P=0.0018$. The distribution of severity of health behavior by gender is shown in Figure 1 .

The level of satisfaction with life is also dependent on gender. Women had a lower level of satisfaction with life than



Figure I IZZ scale (sten) and gender.

Abbreviations: Err Dev, standard error; Std Dev, standard deviation; IZZ, Health Behavior Inventory. men as well. Statistical analysis of the results of the SWLS questionnaire showed that gender affects the satisfaction with life of T2DM patients in a statistically significant way. The test result of $F$ in ANOVA was $F=5.22, P=0.0268$. Women had lower values $(P<0.05)$. The values obtained indicate that men are more likely than women to experience high satisfaction with life. The distribution of satisfaction with life by gender is shown in Figure 2.

Analysis of demographic data showed that age, place of residence, and education level of the respondents do not affect the satisfaction with life and the intensity of health behaviors of patients with T2DM $(P>0.05)$.

The relationship between satisfaction with life and health practices of patients with T2DM is shown in Figures 3 and 4. T2DM patients with a high satisfaction with life had worse health practices in terms of sleep, recreation, and physical activity (Figures 3 and 4). The correlation of scores in the IZZ scale - health practices and the SWLS scores (raw score) was low negative ( $r=-0.3138, P=0.0265$ ) (Figure 3 ). Patients with a higher satisfaction with life had worse health practices. Analogical scores were recorded in the SWLS sten scale (Figure 4). The correlation of scores (sten) was low negative ( $r=-0.3474, P=0.0134)$.

There was a relationship between health practices and satisfaction with life in subjects with T2DM. People with a lower satisfaction with life had better health behaviors (Figure 5). Statistical analysis (test IZZ - health behavior) in terms of gender also showed that women practice better health behaviors (keeping to health recommendations, proper

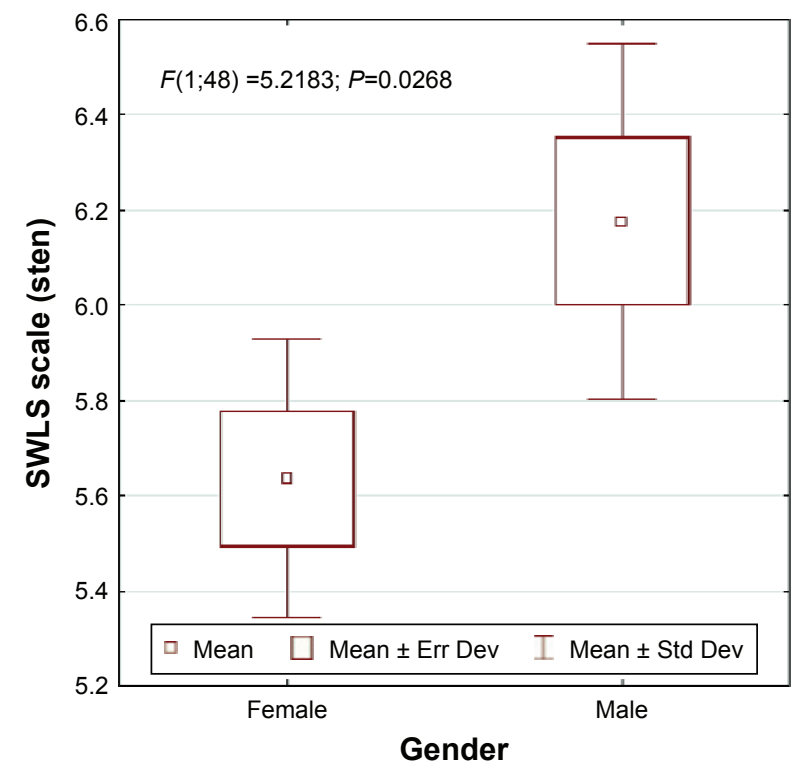

Figure 2 SWLS and gender.

Abbreviations: Err Dev, standard error; Std Dev, standard deviation; SWLS, Satisfaction with Life Scale. 


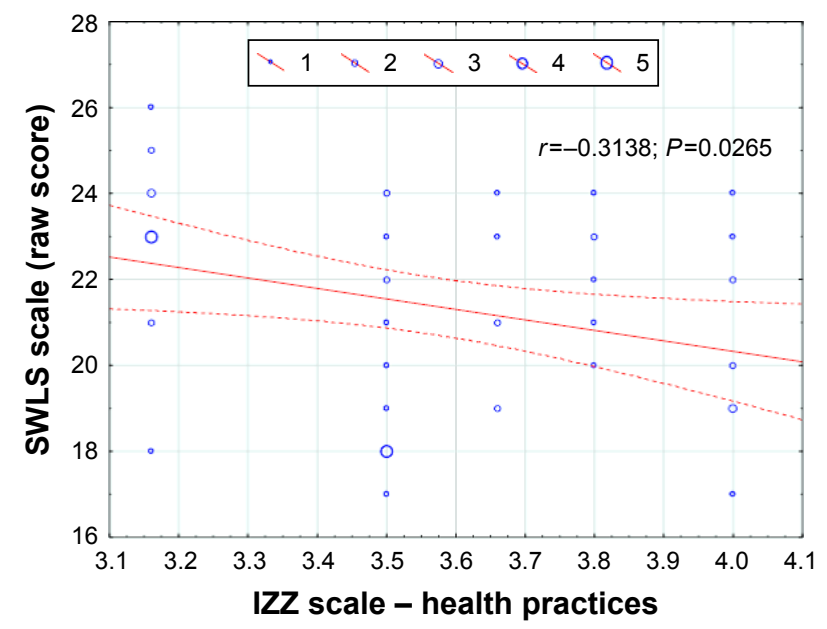

Figure 3 IZZ scale - health practices:SWLS scale (raw score). Abbreviations: IZZ, Health Behavior Inventory; SWLS, Satisfaction with Life Scale.

eating habits, controlling the body weight) than men. The test result of $F$ in ANOVA was $F=7.3047, P=0.095$, with an average of 3.64 for women and 3.41 for men.

The correlation of scores in the IZZ scale - health behaviors and the SWLS scores (sten) was low negative ( $r=-0.2811, P=0.048)$. Patients with a lower satisfaction with life had better health behaviors (Figure 5).

\section{Correlation of scores relating to the $\mathrm{IZZ}$}

The obtained results of existing scores relating to IZZ are presented accordingly in Figures 6-11. Results of this analysis are presented below and in the figures.

Figure 6 shows the correlation of T2DM patients' preventive behaviors and positive mental attitude variables. People with a higher intensity of preventive behaviors were noticed to have a worse mental attitude. The correlation of

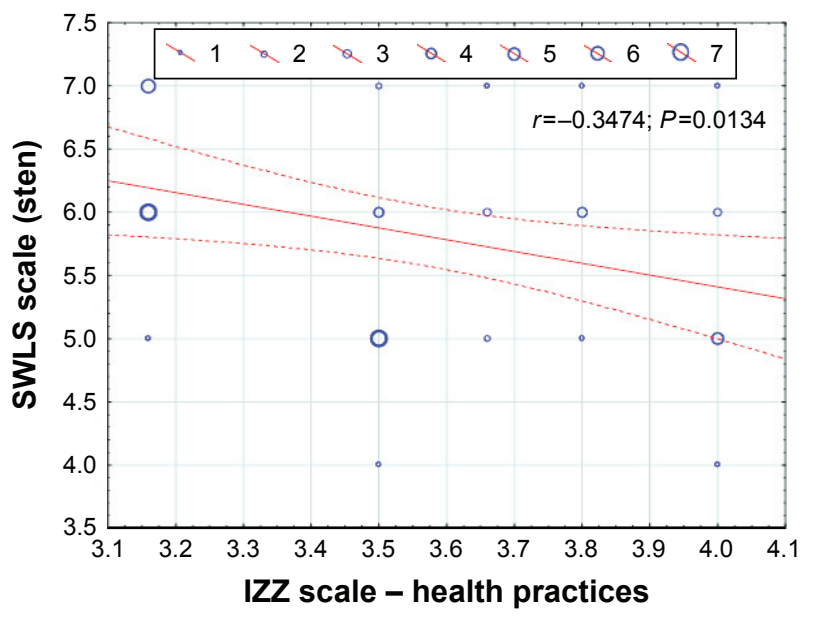

Figure $4 \mathrm{IZZ}$ scale - health practices:SWLS scale (sten).

Abbreviations: IZZ, Health Behavior Inventory; SWLS, Satisfaction with Life Scale.

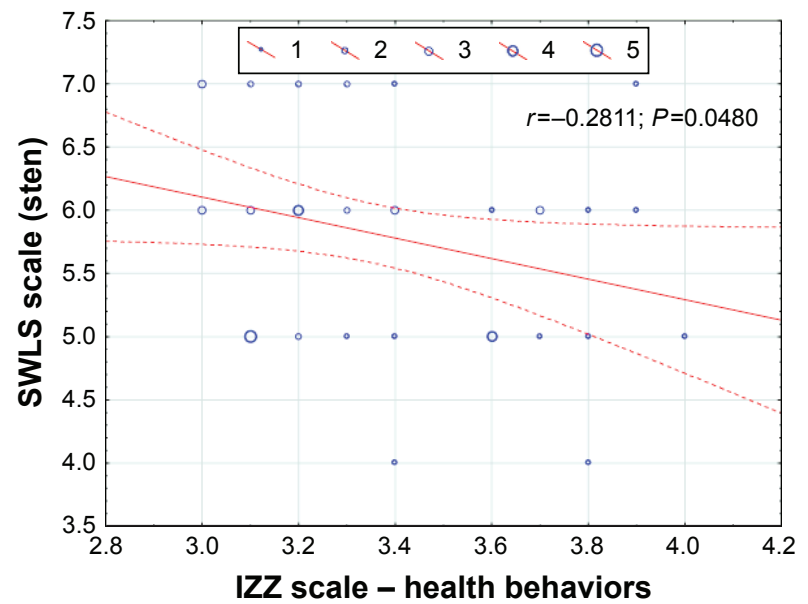

Figure $5 \mathrm{IZZ}$ scale - health behaviors:SWLS scale (sten). Abbreviations: IZZ, Health Behavior Inventory; SWLS, Satisfaction with Life Scale.

scores in the IZZ scale - preventive behaviors and positive mental attitude was low negative $(r=-0.3294, P=0.0195)$ (Figure 6). In terms of gender, better mental attitude was found among men and was higher in them (3.52). Average value of mental attitude coefficient in women was 3.44 , with a standard deviation 0.31 .

Figure 7 shows the correlation of the variables health behaviors and health practices (daily physical activity, recreation, sleeping habits) of a patient diagnosed with T2DM (IZZ).

The correlation of scores in the IZZ scale - health behaviors and health practices (daily physical activity, recreation, sleeping habits) was moderate positive ( $r=0.54$, $P=0.00005)$. Patients with better health practices showed better prohealth behaviors (Figure 7).

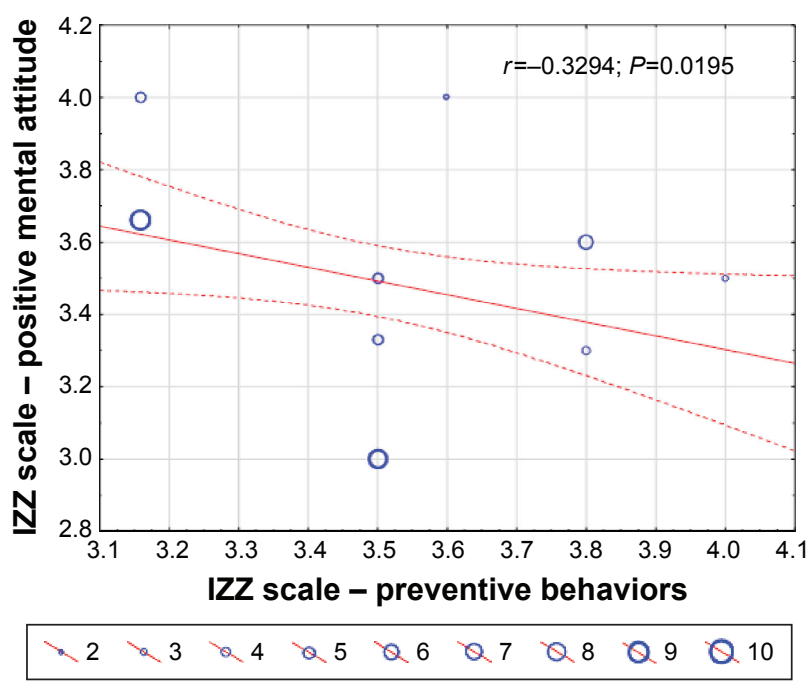

Figure 6 IZZ scale - preventive behaviors:IZZ scale - positive mental attitude. Abbreviation: IZZ, Health Behavior Inventory. 


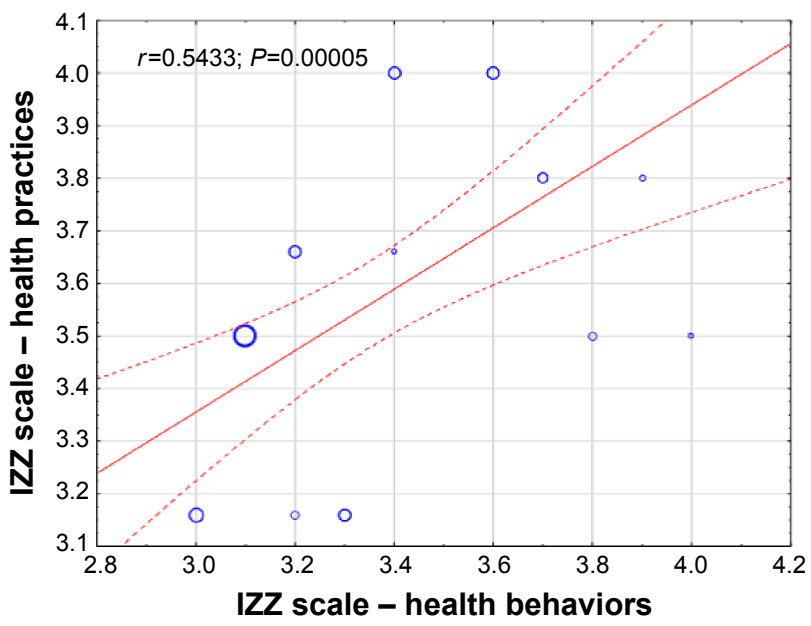

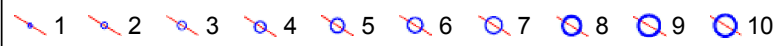

Figure 7 Health behaviors:IZZ scale - health practices.

Abbreviation: IZZ, Health Behavior Inventory.

Figure 8 shows the correlation of the variables health behaviors and preventive behaviors (keeping to health recommendations) of a patient diagnosed with T2DM (IZZ). The correlation of scores in the IZZ scale - health behaviors and preventive behaviors (keeping to health recommendations) was low positive $(r=0.32, P=0.0237)$. Patients with better preventive behaviors showed better health behaviors (Figure 8).

Figure 9 shows the correlation of health behaviors and proper eating habits. Patients with better eating habits showed better health behaviors. The correlation of scores in the IZZ scale - proper eating habits and the scores in the IZZ scale



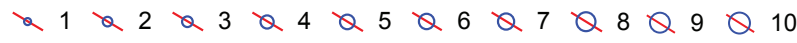

Figure 8 IZZ scale - health behaviors:IZZ scale - preventive behaviors. Abbreviation: IZZ, Health Behavior Inventory.

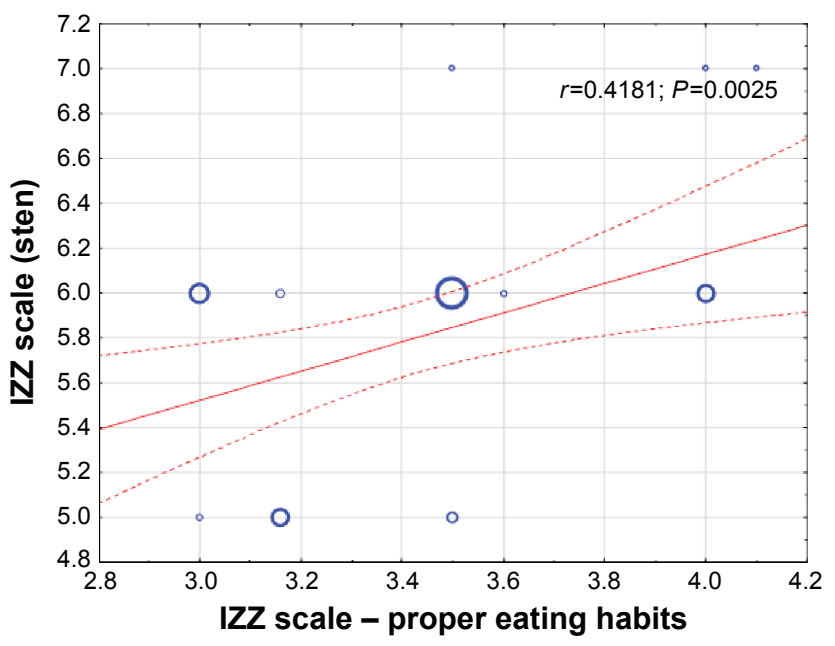

\begin{tabular}{lllllllllllllll}
\hdashline & 1 & $Q$ & 2 & $Q$ & 3 & $Q$ & 4 & $Q$ & 5 & $Q$ & 6 & $Q$ & 7 \\
$Q$ & 8 & $Q$ & 9 & $Q$ & 10 & $Q$ & 11 & $\bigotimes$ & 12 & $\bigotimes$ & 13 & $\ddots$ & 14
\end{tabular}

Figure 9 IZZ scale - proper eating habits:IZZ scale (sten). Abbreviation: IZZ, Health Behavior Inventory.

(sten) was moderate positive $(r=0.418, P=0.0025)$. People with a higher intensity of health behaviors showed better eating habits (Figure 9). Statistical analysis by gender also showed that women had slightly better eating habits than men. Average value for women was 3.45 and for men was 3.38 , with the standard deviation being 0.34 .

Figure 10 shows the correlation of health behaviors to the IZZ scale (sten). The correlation of scores was moderate positive ( $r=0.59, P=0.00001)$.

Figure 11 shows the correlation of preventive behaviors scores to the IZZ scale (sten). The correlation of scores in the IZZ scale - preventive behaviors and the scores in the IZZ



Figure I0 IZZ scale - health behaviors:IZZ scale (sten). Abbreviation: IZZ, Health Behavior Inventory. 


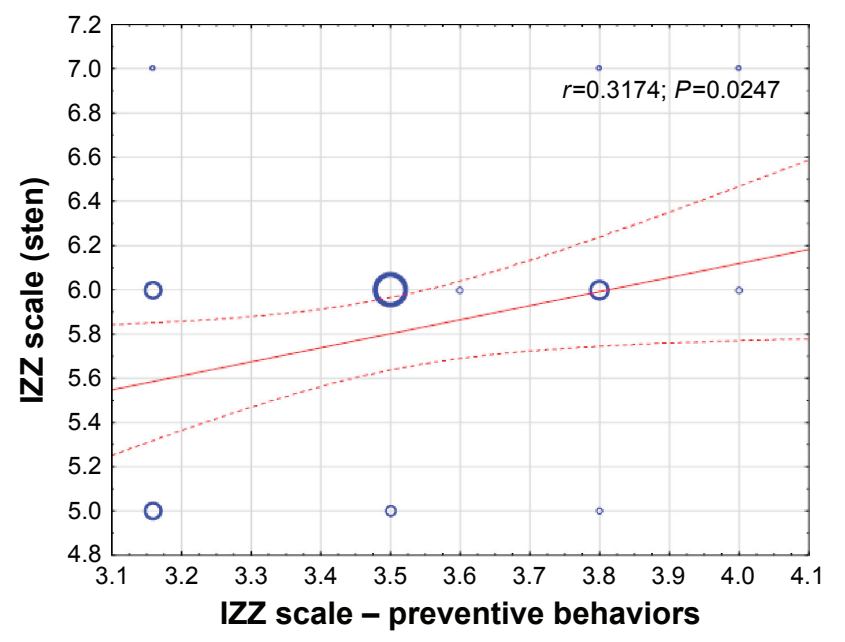

$\begin{array}{lllllllllllllllll} & 1 & Q & 2 & Q & 3 & Q & 4 & Q & 5 & Q & 6 & Q & 7 & Q & 8\end{array}$ $\begin{array}{lllllllllllllllllll}Q & 9 & Q & 10 & Q & 11 & Q & 12 & \bigotimes & 13 & \bigotimes & 14 & \bigotimes & 15\end{array}$

Figure II IZZ scale - preventive behaviors:IZZ scale (sten).

Abbreviation: IZZ, Health Behavior Inventory.

scale (sten) was moderate positive ( $r=0.3174, P=0.0247$ ). T2DM patients who had a higher intensity of health behaviors showed better preventive behaviors.

\section{Discussion}

T2DM negatively impacts health-related quality of life and satisfaction with life.

This negative impact affects multiple aspects of a person's life, including the psychological impact of being chronically ill, dietary restrictions, changes in social life, symptoms of inadequate metabolic control, chronic complications, and ultimately lifelong disabilities. ${ }^{24,45-53}$

Satisfaction with life is a very important factor in the life of a patient with T2DM. ${ }^{54}$ Satisfaction with life translates to better therapeutic effects and improvements in the patient's health. ${ }^{54}$ Health satisfaction is a unique and important concept to consider when developing individualized strategies for managing T2DM because health satisfaction is a key element of patient-centered care. ${ }^{55}$ The concept of diabetes-related health satisfaction encompasses issues specifically related to living with diabetes (eg, blood glucose levels, blood pressure levels, body weight). Health satisfaction is more specific than overall health-related quality of life because it considers disease-related factors. It is different from diabetes treatment satisfaction because it addresses issues not specifically related to treatment. Low levels of health satisfaction in people with T2DM may negatively affect self-care behaviors and treatment outcomes..$^{55}$ The study showed that health behaviors like proper eating habits, preventive behaviors, positive mental attitude, and health practices have an enormous influence on the patient's satisfaction with life.

Furthermore, a relationship was proved to exist between health behaviors and satisfaction with life of the subjects with T2DM. The present study also showed that the gender of the patient $(P<0.05)$ considerably influences both satisfaction with life and the health behaviors of a patient diagnosed with T2DM. Men suffering from T2DM are more satisfied with their lives than women (Figure 2) and are characterized by a higher intensity of health behaviors (Figure 1). This is consistent with the gender differences in health behaviors of patients diagnosed with T2DM and their influence on patients' satisfaction with life reported by other researchers. ${ }^{35-40}$ The health behaviors analyzed in four categories were found to have significant correlation with the analyzed parameters. Among patients with a higher intensity of preventive behaviors, a less positive mental attitude was found. This tendency has also been observed by other researchers. ${ }^{56,57}$ Gender differences have some influence on patients' mental attitude and proper eating habits (consuming vegetables, fruit, whole meal bread). Women with T2DM have worse mental attitude than men with the same illness. Women attach more importance to change of eating habits in the course of the disease than men, which may contribute to greater frustration, dissatisfaction, and worse psychological state. The need to increase physical activity in disease and a tendency to rigorously comply with the doctor's instructions to control the level of glucose can cause worse mental attitude and lower life satisfaction. Often, glycemic control and fear of possible complications in people with T2DM, especially in women, are associated with less positive mental attitude and symptoms of depression. ${ }^{58}$ Chronic metabolic disease involves numerous complications throughout its course, which causes severe restriction and disability in an individual's lifestyle. These disabilities in an individual's life are felt more by women. This may indicate that diabetes and female gender is one of the risk factors in the development of negative mental attitude and depression in this group. Other researchers have shown that the prevalence of clinically relevant depressive symptoms among patients with diabetes (both women and men) is around 30\%. ${ }^{59-61}$ The prevalence of major depressive disorder is approximately $10 \%$, which is double the overall prevalence in people without a chronic medical illness. ${ }^{62,63}$ The low and moderate correlation of eating habits and health practices of T2DM patients suggests that the better the eating habits, the better are the health practices of patients with this diagnosis. This result underlines 
the validity of health education of diabetics. Even though numerous studies discuss health education, no clear relationship between health education and eating habits, health behaviors, or health practices has been shown yet. ${ }^{46}$

Despite the increasing incidence of T2DM globally, the subject of patients' behavior connected to their health and to the general satisfaction with their lives is rarely explored in literature. ${ }^{45,55}$ Proving significant correlation of health behaviors (IZZ) and the results of correlation of the SWLS of patients with T2DM is the basis for further research in this subject. The low negative correlations $(r=-0.28, P<0.05)$ of the IZZ scale scores and the results of the SWLS point to the fact that people who pay attention to health behaviors have focused on the disease and its consequences to such a degree that they have lost satisfaction with their everyday lives. This emotional state was more common among women. ${ }^{64}$ The results of this study confirm the findings of other researchers. ${ }^{56,57,64}$ Lack of satisfaction with life and negative emotions accompanying the disease can be dangerous for T2DM patients, as over time, they may lead to developing other conditions, especially depression. ${ }^{56,57,64}$

Even though patients with T2DM (both women and men) are well prepared for self-care, health education of diabetics should be extended. Health education covering the patients' functioning with a chronic disease aims to improve their emotional state during treatment. ${ }^{65,66}$ Including health education in the process of treatment is especially important for women with a diagnosis of T2DM, as the female gender is a factor which predisposes to a decrease in the level of satisfaction with life.

Diabetes negatively influences the patients' functioning, including their mental state, which undergoes specific changes during the disease course. For the patient to manage the difficulties of the disease, social support aimed at optimizing development, security, fulfilling the developmental needs, and creating comfortable living conditions and conditions for functioning in the society are needed.

The mental state of a patient diagnosed with T2DM influences all aspects of the process of treatment as well as the patient's well-being and satisfaction with life. For this reason, a psychologist is a necessary member of a team of specialists which leads the treatment. Psychological help should cover clear communication with the patient along with continuous evaluation of the patient's mental state and the patient's compliance with the doctors' orders. ${ }^{67,68}$

The influence of diabetes on patient's life and a lack of control over the disease may lead to complications which could disturb the patient's day-to-day life and have a negative impact on the patient's self-esteem. The results of the study also prove that patients characterized by a higher intensity of health behaviors and having a more positive mental attitude experience a much better quality of life in terms of their mental health, in the sense of social relations, and in functioning in the society. ${ }^{54}$

\section{Limitations}

The sample used in this study was restricted to people in Poland with T2DM from 1 to 5 years of diagnosis. Thus, caution should be exercised in generalizing these findings to all people with diabetes. However, the authors are not aware of any reason to believe that people with diabetes longer than 5 years of diagnosis are different from other diabetics in Poland. Limitations of the study also include these elements as the limitations associated with a self-reported, cross-sectional, and correlational design and the limitations associated with the simplicity of utilized statistics. Therefore, there is some potential of bias in reporting the behavior and satisfaction of people with diabetes, which may have occurred because of the respondents' interpretation of the questions or desire to report their behavior and emotions in a certain way, or simply because of the inaccuracies of their responses.

Also, other areas could affect a subject's response to the questionnaire and general health. Although patients with depression as a coexisting disease were excluded from our study, the other coexisting diseases such as heart disease, obesity, hypertension, and also increased pressure before the visit to the doctor (white coat syndrome) and different medications in T2DM treatment could affect a subject's response. We know the main adverse effect of metformin is gastrointestinal discomfort and the major concerns related to the use of sulfonylureas are hypoglycemia and weight gain, which could affect the subjects' responses. There is some potential for reporting the associations between various prohealth behaviors and life satisfaction among individuals with T2DM.

\section{Conclusion}

This study investigates the associations between various health behaviors and life satisfaction among individuals with T2DM. T2DM patients showed limited preventive behaviors, proper eating habits, positive mental attitudes, and health practices. The knowledge of diabetics in the four categories of health behaviors is sufficient for self-care. Health education of people diagnosed with T2DM should be continued, however. The results oscillated around the average, which suggests a need to continue the health education of this group 
of patients. The categorization of the behaviors of diabetics allowed gauging the strength of relationship of the individual categories and satisfaction with life. Male T2DM patients showed a higher satisfaction with life score than women with the same diagnosis. The analyses performed showed that patients with a higher intensity of health behaviors also had better health behaviors. The existing correlations show a significant relationship.

\section{Ethical approval and consent}

The authors declare that the manuscript which was submitted to the journal complies with editorial policies. The authors declare that they comply with the best practice in their field of sharing of data, with particular attention to maintaining patient confidentiality.

\section{Acknowledgments}

This research was not funded and the authors received no grants. The authors would like to thank all contact persons from the participating hospitals of Kuyavian and Pomerania regions (Poland) for distributing and collecting the questionnaires and also the managers of these hospitals for agreeing to this study being conducted in their hospitals.

\section{Author contributions}

All authors contributed toward data analysis, drafting and revising the paper and agree to be accountable for all aspects of the work.

\section{Disclosure}

The authors report no conflicts of interest in this work.

\section{References}

1. World Health Organization. Global Status Report on Non-Communicable Diseases 2014. Geneva; 2014.

2. Bulska J, editor. Health hazard diseases of civilization. Pedagogical contexts Research. Kraków: Publishing House Impuls; 2008:18-19.

3. Sieradzki J. Obesity and Diabetes, Guide for GPs. Poland: TermMedia; 2000;7:90-97.

4. Kokot F, editor. Infectious Diseases. Vol. 2, Warsaw: PZWL; 2006: 1058-1061.

5. Szczeklik A, editor. Interna Szczeklik. Internal Medicine Textbook. Kraków: Practical Medicine; 2012:1360-1361.

6. Rohani H, Eslami AA, Ghaderi A, Bidkhori M, Raei M. Development and psychometric evoluation of a health action process aproach inventory for healthful diet among type 2 diabetes patients. Int J Prev Med. 2016;7:69.

7. Chammas NK, Hill RL, Edmonds ME. Increased mortality in diabetic foot ulcer patients: the significance of ulcer type. J Diabetes Res. 2016; 2016:2879809.

8. Sacks BD, Arnold M, Baknis GL, et al. Guidelines and recommendations for laboratory analisis in the diagnosis and management of diabetes mellitus. Diabetes Care. 2011;34(6):e61-e99.
9. Karłowicz A, Korzon-Burakowska A, Skuratowicz-Kubicka A, Kunicka K, Świerblewska E, Burakowski I. Level of knowledge on diabetic foot in syndrome in typy 2 diabetic patients. Diabetol Pract. 2010; 11(4):109-117.

10. Sieradzki J. Diabetes. Vol. 1, Gdańsk: Via Medica; 2007:300-303.

11. Kawalec P, Kielar M, Pilc A. Costs related to type 1 and 2 diabetes mellitus in Poland. Diabetol Pract. 2006;7(5):287-294.

12. Hu FB. Globalization of diabetes the role of diet, lifestyle, and genes. Diabetes Care. 2011;34(6):1249-1257.

13. Lam DW, LeRoith D. The worldwide diabetes epidemic. Curr Opin Endocrinol Diabetes Obes. 2012;19(2):93-96.

14. Afable A, Karingula NS. Evidence based review of types 2 diabetes prevention and management in low and midle income countries. World J Diabetes. 2016;7(10):209-229.

15. Shaw JE, Sicree RA, Zimmet PZ. Global estimates of the prevalence of diabetes for 2010 and 2010. Diabetes Res Clin Pract. 2010; 87(1):4-14.

16. Reinehr T. Type 2 diabetes mellitus in children and adolescents. World J Diabetes. 2013;4(6):270-281.

17. The Pover of Prevention Chronic Disease ... the public health challenge of th 21st century; 2009. Available from: http://www.cdc.gov/ chronicdisease/pdf/2009-power-of-prevention.pdf

18. Dudzińska M, Tarach JS, Nowakowski A. Measurement of health related quality of life in diabetes melittus. Diabetol Pract. 2011;12(2): $56-64$.

19. Hu J, Wallace DC, Tesh AS. Physical activity, obesity, nutritional health and quality of life in low - income Hispanic adults with diabetes. J Community Health Nurs. 2010;27(2):70-83.

20. Shrestha P, Ghimire L. A review about the effect of life style modyfication on diabetes and quality of life. Glob J Health Sci. 2012;4(6): 185-190.

21. Szymborka-Krajanek T, Koblik T, Bundurska-Stankiewicz E, et al. Metabolic control in type 2 diabetic patients treated by general practitioners and referred to the specialists - preliminary results of the Project "The Improvement of Glyacemic Control". Diabetol Pract. 2009;10(6): 228-233.

22. Korzon-Burakowska A, Adamska K, Skuratowicz-Kubicka A, Jaworska M, Świerblewska E, Kunicka K. Efect of education level on diabetes control and quality of life in insulin - treated type 2 diabetes patients. Diabetol Pract. 2010;11(2):46-53.

23. Rise MB, Pellerud A, Rygg L, Steinsbekk A. Making and maintaining lifestyle changes after participating in group based type 2 diabetes self-management educations: a qualitative study. PLoS One. 2013;8(5):e64009.

24. Rubin RR, Peyrot M. Quality of life and diabetes. Diabetes Metab Res Rev. 1999;15(3):205-218.

25. Rose M, Burkert U, Scholler G, Schirop T, Danzer G, Klapp BF. Determinants of quality of life of patients with diabetes under intensified insulin therapy. Diabetes Care. 1998;21(11):1876-1883.

26. Andrews FM, Withey SB. Developing measures of perceived life quality: results from several national surveys. Soc Indic Res. 1974;1: $1-26$.

27. Mastekaasa A. Multiplicative and additive models of job and life satisfaction. Soc Indic Res. 1984;14:141-163.

28. Aalto AM, Uutela A, Aro AR. Health related quality of life among insulin-dependent diabetics: disease-related and psychosocial correlates. Patient Educ Couns. 1997;30(3):215-225.

29. Wredling R, Stalhammar J, Adamson U, Berne C, Larsson Y, Oestman J. Well-being and treatment satisfaction in adults with diabetes: a Swedish population-based study. Qual Life Res. 1995;4(6):515-522.

30. Eiser C, Flynn M, Green E, et al. Quality of life in young adults with type 1 diabetes in relation to demographic and disease variables. Diabet Med. 1992;9(4):375-378.

31. Lewis KS, Bradley C, Knight G, Boulton AJ, Ward D. A measure of treatment satisfaction designed specifically for people with insulindependent diabetes. Diabet Med. 1988;5(3):235-242. 
32. Glasgow RE, Ruggiero L, Eakin EG, Dryfoos J, Chobanian L. Quality of life and associated characteristics in a large national sample of adults with diabetes. Diabetes Care. 1997;20(4):562-567.

33. Klein BE, Klein R, Moss SE. Self-rated health and diabetes of long duration. the wisconsin epidemiologic study of diabetic retinopathy. Diabetes Care. 1998;21(2):236-240.

34. Peyrot M, Rubin RR. Levels and risks of depression and anxiety symptomatology among diabetic adults. Diabetes Care. 1997;20(4):585-590.

35. Mazze RS, Lucido D, Shamoon H. Psychological and social correlates of glycemic control. Diabetes Care. 1984;7(4):360-366.

36. Verbrugge LM. Sex differences in health. Public Health Rep. 1982; 97(5):417-437.

37. Hibbard JH, Pope CR. Gender roles illness orientation and use of medical services. Soc Sci Med. 1983;17(3):129-137.

38. Kandrack M, Grant KR, Segall A. Gender differences in health-related behaviour: some unanswered questions. Soc Sci Med. 1991;32(5): 579-590.

39. Verbrugge LM. Gender and health: an update on hypotheses and evidence. J Health Soc Behav. 1985;26(3):156-183.

40. Rubin RR, Peyrot M. Men and diabetes: psychosocial and behavioral issues. Diabetes Spectr. 1998;11(2):81-87.

41. Psychometric Success. Available from: http://www.psychometricsuccess.com/aptitude-tests/percentiles-and-norming.htm\#sthash. tTOnwq2f.dpuf. Accessed March 10, 2016.

42. Juczyński Z. Measurement Tools in the Promotion and Psychology Health. Laboratory of Psychological Tests: Warsaw; 2009:110-116.

43. Pavot W, Diener E. The satisfaction with life scale and the emerging construct of life satisfaction. $J$ Posit Psychol. 2008;3(2):137-152.

44. Kobau R, Sniezek J, Zack MM, Lucas RE, Burns A. Well-being assessment: an evaluation of well-being scales for public health and population estimates of well-being among US adults. Appl Psychol Health Well Being. 2010;2(3):272-297.

45. Deshpande AD, Harris-Hayes M, Schootman M. Epidemiology of diabetes and diabetes-related complications. Phys Ther. 2008;88(11):1254-1264.

46. Coppola A, Sasso L, Bagnasco A, Giustina A, Gazzaruso C. The role of patient education in the prevention and management of type 2 diabetes: an overview. Endocrine. 2016;53(1):18-27.

47. Demirci H, Cinar Y, Bayram N, Bilgel N. Quality of life in type II diabetic patients in primary health care. Dan Med J. 2012;59(10):A4468.

48. Bradley C, de Pablos-Velasco P, Parhofer KG, Eschwege E, GonderFrederick L, Simon D. PANORAMA: a European study to evaluate quality of life and treatment satisfaction in patients with type-2 diabetes mellitus - study design. Prim Care Diabetes. 2011;5(4):231-239.

49. Koopmanschap M. Coping with Type II diabetes: the patient's perspective. Diabetologia. 2002;45(7):S18-S22.

50. Mata Cases M, Roset Gamisans M, Badia Llach X, Antoñanzas Villar F, Ragel Alcázar J. Impacto de la diabetes Mellitus tipo 2 en la calidad de vida de los pacientes tratados en las consultas de atención primaria en España (Effect of type-2 diabetes mellitus on the quality of life of patients treated at primary care consultations in spain). Aten Primaria. 2003;31(8):493-499. Spanish.

51. Jacobson AM. The psychological care of patients with insulin-dependent diabetes mellitus. $N$ Engl J Med. 1996;334(19):1249-1253.
52. Hornquist JO, Wikby A, Stenstrom U, Andersson PO, Akerlind I. Type II diabetes and quality of life: a review of the literature. Pharmacoeconomics. 1995;8(Suppl 1):12-16.

53. Aguiar CC, Vieira AP, Carvalho AF, Montenegro-Junior RM. [Assessment instruments for a Health-Related Quality of Life in diabetes mellitus]. Arq Bras Endocrinol Metabol. 2008;52(6):931-939.

54. Kurowska K, Szomszor M. The impact of health behaviours on the quality of life of patients diagnosed with type 2 diabetes. Diabetol Pract. 2011;12(4):142-150.

55. Traina SB, Colwell HH, Crosby RD, Mathias SD. Pragmatic measurement of health satisfaction in people with type 2 diabetes mellitus using the current health satisfaction questionnaire. Patient Relat Outcome Meas. 2015;6:103-115.

56. Rodríguez Calvín JL, Gaviria ZA, Ríos M. Prevalence of depression in type 2 diabetes mellitus. Rev Clin Esp. 2015;215(3):156-164.

57. Shehatah A, Rabie MA, Al-Shahry A. Prevalence and correlates of depressive disorders in elderly with type 2 diabetes in primary health care settings. J Affect Disord. 2010;123(1-3):197-201.

58. Bădescu SV, Tătaru C, Kobylinska L, et al. The association between diabetes mellitus and depression. J Med Life. 2016;9(2):120-125.

59. Robinson DJ, Luthra M, Vallis M. Canadian diabetes association clinical practice guidelines expert committee. Canadian diabetes association 2013 clinical practice guidelines for the prevention and management of diabetes in Canada. Can J Diabetes. 2013;37(suppl 1):S1-S212.

60. Ali S, Stone MA, Peters JL, Davies MJ, Khunti K. The prevalence of co-morbid depression in adults with type 2 diabetes: a systematic review and meta-analysis. Diabet Med. 2006;23(11):1165-1173.

61. Barnard KD, Skinner TC, Peveler R. The prevalence of co-morbid depression in adults with type 1 diabetes. Diabet Med. 2006;23(4): 445-448.

62. Egede LE. Diabetes, major depression, and functional disability among US adults. Diabetes Care. 2004;27(2):421-428.

63. Moussavi S, Chatterji S, Verdes E, Tandon A, Patel V, Ustun B. Depression, chronic diseases, and decrements in health: results from the world health surveys. Lancet. 2007;370(9590):851-858.

64. Kokoszka A, Pouwer F, Jodko A, et al. Serious diabetes-specific emotional problems in patients with type 2 diabetes who have different levels of comorbid depression: a Polish study from the European depression in diabetes (EDID) research consortium. Eur Psychiatry. 2009;24(7):425-430.

65. Kueh YC, Morris T, Ismail AA. The effect of diabetes knowledge and attitudes on self-management and quality of life among people with type 2 diabetes. Psychol Health Med. Epub 2016 Feb 5.

66. Kueh YC, Morris T, Borkoles E, Shee H. Modelling of diabetes knowledge, attitudes, self-management, and quality of life: a cross-sectional study with an Australian sample. Health Qual Life Outcomes. 2015; 13:129.

67. Kurowska K, Frąckowiak M. Social suport and coping with chronic disease as exemplified by type 2 diabetes. Diabetol Pract. 2010; 11(3):101-107.

68. Polish Diabetes Association. Clinical Recommendations for the management of patients with diabetes in 2009. Pract Diabetol. 2009; 10(Suppl A): 15
Therapeutics and Clinical Risk Management

\section{Publish your work in this journal}

Therapeutics and Clinical Risk Management is an international, peerreviewed journal of clinical therapeutics and risk management, focusing on concise rapid reporting of clinical studies in all therapeutic areas, outcomes, safety, and programs for the effective, safe, and sustained use of medicines. This journal is indexed on PubMed Central, CAS,
Dovepress

EMBase, Scopus and the Elsevier Bibliographic databases. The manuscript management system is completely online and includes a very quick and fair peer-review system, which is all easy to use. Visit http://www.dovepress.com/testimonials.php to read real quotes from published authors. 